ISSN 2236-0859

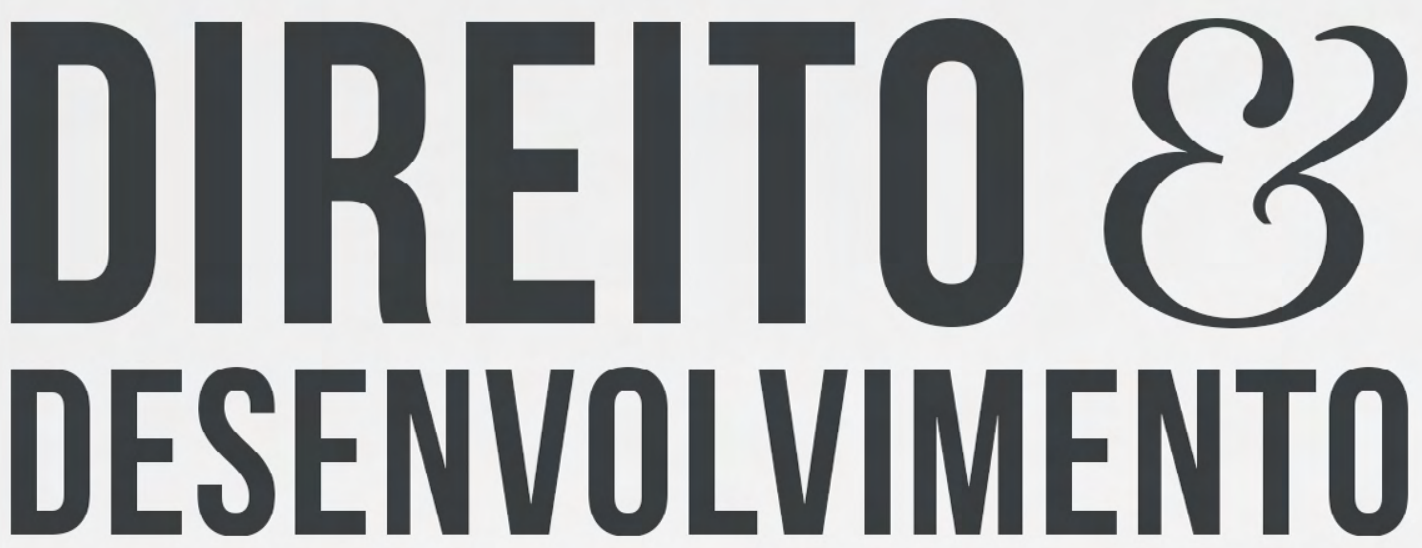

REVISTA DO PROGRAMA DE PÓS-GRADUAÇÃO EM DIREITO MESTRADO EM DIREITO E DESENVOLVIMENTO SUSTENTÁVEL

A ABUSIVIDADE DA MAJORAÇ̃̃O DOS HONORÁRIOS MÉDICOS EM RAZÃO DA MUDANÇA DE ACOMODAÇÃO DO CONSUMIDOR-PACIENTE

IGOR DE LUCENA MASCARENHAS

ALFREDO RANGEL RIBEERO 


\title{
A ABUSIVIDADE DA MAJORAÇÃO DOS HONORÁRIOS MÉDICOS EM RAZÃO DA MUDANÇA DE ACOMODAÇÃO DO CONSUMIDOR-PACIENTE
}

\section{THE ABUSIVENESS OF THE INCREASING THE MEDICAL FEES DUE A CHANGE OF ACCOMMODATION OF THE CONSUMER- PATIENT}

Recebido: 29/07/2018

Igor de Lucena Mascarenhas*

Aprovado: 23/10/2018

Alfredo Rangel Ribeiro**

RESUMO: O presente trabalho discorre sobre os honorários médicos ea permissão, pelo Conselho Federal de Medicina, da majoração dos honorários médicos em caso de opção do paciente por acomodação superior. Apesar de existir precedente do Superior Tribunal de Justiça considerando legítima tal conduta, observa-se uma atuação pendular do Judiciário, de modo que ainda não há um posicionamento firme e claro sobre a temática. Por intermédio da análise bibliográfica, conclui-se que, por se tratar de serviço idêntico, não há razão para a cobrança diferenciada e, portanto, a majoração dos honorários médicos seria abusiva e contrária ao Código de Defesa do Consumidor.

Palavras-chave: Relação médico-paciente. Honorários médicos. Majoração por mudança de acomodação. Abusividade. Tratamento não isonômico.

\begin{abstract}
The paper discusses the medical fees and the authorization by the Federal Medical Council to increase it in case of an upgrade of the hospital accommodation. The Superior Court of Justice already decided an individual case and ruled that the medical conduct is legal e legitimate, however, based on cases analyzed by the states courts, there is a pendulary action of the Judiciary, so that there is no firm and clear position on the issue. Through a bibliographic analysis, it is concluded that, because it is an identical service, there is no reason for differentiated charging and, therefore, the medical posture would be abusive and contrary to the Consumer Defense Code.
\end{abstract}

Keywords: Physician-patient relationship. Medical fees. Increasing due change of accommodation. Abusiveness. Non-isonomic Treatment.

\section{INTRODUÇÃO}

A exemplo do que ocorre com outras profissões, a nobreza dos misteres da medicina tende a conferir-lhe natureza não mercantilista. Nesta perspectiva, ainda bastante influenciada pelo ideal ético-profissional ligado às origens das profissões da saúde, o ato médico não tem

* Mestre Ciências Jurídicas pela Universidade Federal da Paraíba. Especialista em Direito Civil Constitucional pela Universidade Federal da Paraíba. Professor do Centro Universitário Unifacisa e das Faculdades Integradas de Patos (FIP). Membro do Instituto Perspectivas e Desafios de Humanização do Direito Civil Constitucional (IDCC). Membro do Associação Brasileira de Direito e Economia (ABDE). Advogado. E-mail: imascarenhas@mbrp.adv.br

** Doutor e Mestre em Direito pela Universidade Federal da Paraíba, com Doutorado Sanduíche junto à Universidade do Minho (Braga-Portugal). Professor Adjunto do Departamento de Direito Privado da Universidade Federal da Paraíba. Professor Titular do Departamento de Direito do Centro Universitário de João Pessoa. E-mail: alfredo@santiagorangel.adv.br 
preço, mas honra, dando ensejo aos honorários médicos. Nada obstante, hodiernamente as atividades médicas vêm sendo exploradas por agentes econômicos em contexto de mercado, o que levou o Superior Tribunal de Justiça (STJ) a reconhecer o caráter consumerista da relação médico-paciente.

Com o objetivo de evitar o aviltamento dos honorários médicos e manter a dignidade da profissão, o Conselho Federal de Medicina (CFM) editou a Resolução no 1673/2003, permitindo que os Conselhos Regionais fixassem valores mínimos para os atos médicos previstos na Classificação Brasileira Hierarquizada de Procedimentos Médicos (CBHPM), que admite majoração dos honorários médicos caso o consumidor-paciente opte por acomodações superiores àquelas previstas em seu plano de saúde.

Este permissivo finda por admitir cobrança diferenciada por idênticos serviços, prática considerada abusiva pelo Código de Defesa do Consumidor (CDC). Ademais, em regra a majoração dos honorários médicos por acomodação superior não é informada previamente ao consumidor, que é surpreendido com sua cobrança justamente quando se encontra em estado de vulnerabilidade agudizada pela enfermidade que o acomete.

Apesar de existir precedente do STJ considerando legítima a majoração dos honorários em caso de acomodações hospitalares superiores, tal prática continua sendo considerada abusiva por tribunais estaduais e sofrendo fortes críticas doutrinárias.

Neste contexto, fazendo uso dos métodos analítico, dedutivo, dialético e hermenêutico, o presente estudo, partindo de uma perspectiva histórica, perquire, por meio de pesquisa exploratória de fontes diretas, da literatura científica e de precedentes judiciais, sobre a incompatibilidade da majoração de honorários médicos em caso de opção por acomodações superiores.

O texto será segmentado em o6 (seis) seções, incluindo a introdução e as considerações finais. Inicialmente, serão abordados os honorários médicos e, em sequência, sua complementação em razão da mudança de acomodação do paciente em categoria superior à contratada. Em seguida, a questão será analisada sob a perspectiva do dever de informar dos planos de saúde. A abusividade da majoração dos honorários médicos à luz do Direito do Consumidor será objeto do último item.

\section{DOS HONORÁRIOS MÉDICOS}

Ainda que a Medicina seja considerada um múnus público, nos termos do Código de Ética Médica (CEM/2010), as atividades do profissional de Medicina podem se desenvolver no contexto do exercício de atividade lucrativa. Neste caso, os honorários médicos se consubstanciam como meio de subsistência no sistema produtivo existente.

Entender que os honorários não seriam direito do médico equivale a negar a existência digna e a sobrevivência do profissional. A remuneração está associada à sua subsistência e à necessidade de manutenção de suas necessidades básicas (FRANÇA, 2010).

França (2013), apresentando uma visão romântica do exercício da medicina, pontifica que o seu exercício não deve visar ao lucro, de modo que os honorários representariam apenas a consequência do agir médico, não se confundindo com o objetivo fundamental, que é a promoção do bem do paciente ${ }^{2}$. Sob esse prisma, o CEM/2010 idealiza que o exercício da medicina deve estar dissociado da prática mercantil, de sorte a não se pautar por regras estritamente capitalistas, mas pelos princípios da dignidade da pessoa e da saúde humana, vejamos:

2 Em paralelo, apesar da visão idealista externada, o autor defende que há uma crescente valorização do profissional de medicina, gerando uma situação econômico-social para o médico, se comparado com os demais membros da sociedade (FRANÇA, 2013). 


\section{I - PRINCÍPIOS FUNDAMENTAIS}

I - A Medicina é uma profissão a serviço da saúde do ser humano e da coletividade e será exercida sem discriminação de nenhuma natureza.

II - O alvo de toda a atenção do médico é a saúde do ser humano, em benefício da qual deverá agir com o máximo de zelo e o melhor de sua capacidade profissional.

III - Para exercer a Medicina com honra e dignidade, o médico necessita ter boas condições de trabalho e ser remunerado de forma justa.

É vedado ao médico:

Art. 58. O exercício mercantilista da Medicina. (grifo nosso)

Apesar de a Medicina não dever ser mercantilizada, o desempenho das atividades médicas vem crescentemente se inserindo em perspectiva empresarial, afastando-se daquele padrão sacro e desinteressado prescrito pela deontologia médica. Atualmente, a Medicina passa a ser observada como uma Ciência cujo objetivo é a saúde humana, cuja eficácia pode ser potencializada se inserida em ambiente mercadológico, convertendo o ato médico em serviço oferecido no mercado de consumo mediante remuneração (SZAFIR, 2015).

Aquela visão sacerdotal da medicina, em parte, está associada ao desenvolvimento histórico da "arte médica", originalmente associada ao xamanismo ou curandeirismo médico, em que o profissional de saúde era uma espécie de interventor divino da Terra, cabendo-lhe minorar a dor e o sofrimento do paciente (PEREIRA, 2015). Seu insucesso adviria dos desígnios divinos ao passo que seu êxito decorreria da intervenção milagrosa por meio das práticas protomedicinais. Ou seja, o curandeiro ostentava espécie de aura celestial, concentrando, por vezes, poder religioso ou mesmo temporal. Desta forma, na qualidade de interventor superior, aquele que exercia o mister da cura assumia certo grau de imunidade que inviabilizava o questionamento de suas atuações. Por essa razão, o médico ainda hoje tende a ser idealizado como pessoa vocacionada a minorar a dor dos membros da coletividade (KFOURI NETO, 2013).

Pode-se afirmar que a Medicina se originou dessa aura sobrenatural, em que pese os "médicos" antigos serem homens que, por meio do conhecimento consuetudinário imemorial, desenvolveram métodos de cura e diminuição do sofrimento humano (MELO, 2014).

Compartilhando do entendimento exposto no CEM/2010, Pedro Fonseca e Maia Paula Fonseca (2016) pontificam que a medicina é profissão que tem como objetivo o tratamento do ser humano e prestação de serviço de saúde. Não haveria espaço para uma atuação egoísta ou pessoalizada, pois o agir médico seria em benefício do paciente e da coletividade, não comportando, desta forma, a exploração mercantil dessa nobre atividade.

Considerando esse aspecto histórico, a medicina-sacerdócio não comportaria pagamentos que variassem de acordo com a condição financeira do beneficiado ou oscilassem de acordo com as leis de mercado3 ${ }^{3}$ Essa visão romântica estipula que o valor da contraprestação paga ao médico há de ser justo, mas jamais lucrativo. Por isso denominam-se "honorários" aquilo que é relativo à honra ${ }^{4}$ - o valor devido a tais profissionais, evitando-se termos como remuneração ou salário.

3 Em sentido contrário já se posicionou o CFM nos autos do Processo 1187/2007 ao destacar que "o médico que cobra seus honorários e da sua equipe considerando as circunstâncias, prática local e a situação econômica de quem trata os valores, não pode ser considerado infrator do CEM" (CFM, 2008, p. 149). Cf. CFM. APELAÇÃO: 1187. Relator: Conselheiro Wirlan de Santos da Luz. CFM. D.O.U 01/02/2008, Seção 1, Página 149. Disponível em: <http://www.portalmedico.org.br/jurisprudencia/detalhes.asp?COD=5023\&chave=CRM-SP\&numero=1187>. Acesso em: 10 mar. 2018.

4 Sobre essa discussão sobre o uso dos substantivos "honorários" ou "remuneração professional", é necessário destacar que o CEM/2010 
Tratando sobre caso análogo (honorários advocatícios), Martins (2010) destaca que há profissões que não são comportadas pelo mercado, sobretudo ante a sua relação direta para com a honra:

\begin{abstract}
O advogado não recebe subsídios, como os servidores públicos, nem salários, mas honorários. E vale a pena relembrar a origem do vocábulo, que vem da antiga Roma, onde causídicos recebiam honrarias para a defesa de seus constituintes, pois poder contar com um defensor, no direito romano, significava estar sendo defendido por alguém que se colocava acima dos interesses momentâneos, econômicos, pessoais ou políticos, sendo capaz de enfrentar os poderosos. A atuação de Cícero talvez tenha sido a mais bela expressão da advocacia, ainda no tempo da República. Por isto, os advogados não recebiam contraprestação, mas honrarias decorrentes de terem aceito a defesa, mormente em nível de pecúnia (MARTINS, 2010).
\end{abstract}

Desta forma, a partir da leitura do art. 58 do CEM/2010, Dantas e Coltri (2010) pontificam que o não exercício mercantilista não é incompatível com o recebimento de honorários. Para eles, o que é violador da ética é a cobrança de honorários vis e extorsivos, em que o profissional de medicina utilize os seus honorários como meio de competição no mercado. O recebimento de honorários é um direito médico, cabendo ao órgão de fiscalização profissional coibir cobranças exageradas, sejam elas para além ou para aquém do patamar que se entende por razoável, de sorte que sua fixação é norteada por parâmetros de justiça e dignidade.

Apesar da dignidade da qual se reveste a medicina, o atual estágio de profissionalização e organização dos agentes econômicos que fornecem serviços de saúde no mercado (hospitais, clínicas, planos de saúde, cooperativas, médicos e outros) levaram a jurisprudência a reconhecer o caráter consumerista da relação médico-paciente (BRASIL, 2015) e a aplicabilidade do CDC aos planos de saúde 5 , exceto àqueles administrados por entidades de autogestão.

Para fins do presente estudo, é necessário que se defina o que vem a ser a remuneração médica e qual o alcance da "justiça" remuneratória. Nos termos do Código Civil, os honorários médicos devem ser interpretados como a retribuição pecuniária em razão de um serviço médico prestado. A partir da leitura dos seus artigos 593 e seguintes, observa-se que há um serviço prestado (serviço médico) e que este representa uma obrigação de fazer, sendo a contraprestação devida ao profissional no âmbito da autonomia contratual.

Ao conceituar os honorários médicos, França (2013, p. 153) destaca que:

É chamada de honorários a justa remuneração paga pelos serviços prestados ao paciente, quando em clínica privada. Tem essa denominação em face de não existir uma equivalência entre a retribuição monetária e um bem de tão alto valor, como a vida ou a saúde. Fica o doente, portanto, obrigado à consideração por tais benefícios.

Em regra, a pactuação dos honorários é feita de forma verbal. Por vezes, tal valor é acordado por telefone no momento do agendamento da consulta e, frequentemente, tende a não ensejar controvérsias ${ }^{6}$, exceto quando se trata de honorários complementares ou para casos específicos.

O Conselho Regional de Medicina do Estado de Santa Catarina (20oo, [s.p.]) editou recomendação sugerindo que o arbitramento dos honorários médicos deve se pautar pelos seguintes elementos:

utiliza de forma indistinta as duas nomenclaturas.

5 Súmula 608 do Superior Tribunal de Justiça: “Aplica-se o Código de Defesa do Consumidor aos contratos de plano de saúde, salvo os administrados por entidades de autogestão".

6 De acordo com Calado (2014), a liberdade das formas constante no ordenamento português e brasileiro são mecanismos de facilitação das transações. 


\begin{abstract}
No arbitramento dos seus honorários, o médico deve levar em conta a praxe do lugar, as posses do paciente, a hora, o meio de locomoção e, principalmente, o valor intrínseco do trabalho executado e a complexidade do caso. Estas considerações valem mais para os chamados domiciliares, os tratamentos de longa duração sobretudo se domiciliares e as cirurgias, do que propriamente para as consultas médicas em consultório.
\end{abstract}

Para França (2010, 2013), há seis elementos que podem nortear a fixação dos honorários, quais sejam: a) condição econômica do paciente; b) fama do profissional; c) valor do trabalho; d) local e hora do trabalho; e) usos e costumes do lugar, e; f) êxito dos serviços prestados. Todavia, a subjetividade inerente à aferição de tais parâmetros não traz patamares concretos e objetivos, comprometendo a verificação da eticidade e justiça da verba honorária. Ou seja, o valor do ato médico, ante a falta de critérios éticos e jurídicos concretos, passa a ser objeto de questionamentos nas esferas cível, criminal e administrativa, ensejando o que Raposo (2013) chamou de "problema jurídico".

\title{
2.1 JUSTIÇA E ETICIDADE NA FIXAÇÃO DOS HONORÁRIOS MÉDICOS
}

De acordo com Cherchiglia (1994), há duas formas típicas de remuneração do trabalho médico: a remuneração por resultado (RPR) ou o sistema de remuneração por tempo, sendo esta última forma mais frequente pois, segundo médicos e gestores de saúde, supostamente garante maior segurança aos contratantes.

Observa-se, consoante já exposto no item anterior, que não havia um critério objetivo para regular a eticidade e a justeza no arbitramento do valor dos honorários médicos. As orientações e critérios até então existentes, ante sua considerável abstração, não ofereciam a objetividade e a segurança necessárias na fixação da contraprestação devida ao médico.

Todavia, movimento iniciado pelo Conselho Federal de Medicina, por meio da Resolução CFM no ${ }^{1673 / 2003}$, fez com que alguns Conselhos Regionais de Medicina, a exemplo da Paraíba e Espírito Santo ${ }^{7}$, editassem atos normativos estabelecendo objetivamente valores mínimos para os atos médicos previstos na "Classificação Brasileira Hierarquizada de Procedimentos Médicos".

A CBHPM é um manual editado pela Associação dos Médicos do Brasil (AMB) com o apoio do CFM e da Federação Nacional dos Médicos e cujo acesso a cada edição revisada é feito pelo sítio da instituição. Desta forma, atualmente, os próprios médicos definem o valor mínimo tido como justo e ético, apesar de as partes terem liberdade para fixar valores superiores a depender das peculiaridades do caso concreto.

A partir daí, a exemplo do que há muito ocorre com outras categorias profissionais ${ }^{8}$, o médico que cobrar valores inferiores ao estabelecido na CBHPM viola a Ética Médica e incorre em infração disciplinar, sujeita a sanções administrativas, vez que o valor mínimo ali fixado concretiza o conceito de justiça trazido no $\mathrm{CEM} / 2010$ e seu aviltamento compromete a dignidade da profissão.

7 O CRM/PB editou a Resolução 119/2004 e o CRM-ES editou a Resolução 154/2004, que também fixavam a CBHPM como parâmetro ético mínimo

$8 \mathrm{O}$ artigo 58, V, da Lei 8.906/94 e o art. 11 do Regulamento Geral da Ordem dos Advogados do Brasil (OAB) preveem que os Conselhos Seccionais da OAB editarão tabelas de honorários mínimos. No mesmo sentido, a Lei 6.530/78, o Decreto n.o 81.871/78 (art. 16, VIII) e o Código de Ética Profissional do Conselho Federal dos Corretores de Imóveis autorizam os Conselhos Regionais dessa categoria profissional a fixar os valores mínimos de remuneração em cada estado. 


\section{A COMPLEMENTAÇÃO DOS HONORÁRIOS MÉDICOS POR ACOMODAÇÕES HOSPITALARES SUPERIORES}

Um dos marcos para a disputa entre médico e paciente na fixação de honorários profissionais surgiu na década de 80 , quando o Estado brasileiro, objetivando a participação de grandes empresas na assistência à saúde pública, definiu que seria possível a cobrança complementar de honorários médicos em caso de acomodação superior àquela custeada pelo Poder Público.

Menicucci (2007) destaca que as Portarias 2079/1980/INAMPS e MPAS 2837/1982 tiveram como efeito a transferência voluntária ou forçosa da população para acomodações superiores, o que legitimaria as unidades de saúde a cobrar diretamente da população o serviço tido como complementar. Ocorre que essa cobrança complementar representava, na prática, o compartilhamento dos custos entre o Estado e o particular, pois as taxas hospitalares, preços de diárias e honorários médicos nas denominadas "acomodações especiais" ensejavam majoração média de $100 \%$ (cem por cento) do valor pago pela Administração.

Destaque-se que, conforme entendimento de Matos e Paim (2015), a diferença de classe no âmbito público seria plenamente legítima, pois compatibilizaria o interesse público e privado. O direito à saúde, enquanto interesse público, não seria inconciliável ao direito ao conforto e a um tratamento médico melhor. O texto constitucional estabeleceria um piso mínimo de direitos, aí incluído o direito ao tratamento digno, o que não contempla acomodações especiais, contratadas e cobradas separadamente, observada a proporcionalidade.

Essa mesma premissa de complementação de honorários vige atualmente na CBHPM, de sorte que o valor dos honorários médicos está atrelado não apenas ao serviço médico prestado, mas também ao nível da acomodação do paciente.

A CBHPM estabelece o percentual mínimo para acomodações coletivas, todavia, prevê também que o valor dos honorários deve ser majorado em caso de opção por "acomodações hospitalares superiores":

6.1 Quando o paciente voluntariamente internar-se em ACOMODAÇÕES HOSPITALARES SUPERIORES, diferentes das previstas no item 1.5 destas Instruções e do previsto em seu plano de saúde original, a valoração do porte referente aos procedimentos será complementada por negociação entre o paciente e o médico, servindo como referência o item 6.2 destas Instruções (ASSOCIAÇÃO MÉDICA BRASILEIRA, 2012, p. 19).

Logo, o cerne da discussão reside na eventual abusividade da complementação de honorários médicos em caso de mudança de acomodação para níveis superiores. Em outras palavras, é possível majorar a remuneração devida ao mesmo profissional que realiza idêntico atendimento, pelo simples fato de o paciente ter optado por aposentos superiores?

Tepedino (2010) salienta que a Constituição Federal e o CDC buscam a defesa de valores existenciais do consumidor no mercado. Desta forma, em que medida um ato administrativo regulamentar (CBHPM) poderia impor condição mais gravosa a consumidores que melhoram suas acomodações, sem que haja qualquer ônus para a classe médica?

O caso em que tal controvérsia se verifica com maior recorrência é o da parturiente que deseja ascender da enfermaria ou quartos duplos para unidades individuais (apartamentos). No momento de maior vulnerabilidade e graça humana, o parto, a família em constituição é surpreendida com a cobrança da complementação dos honorários sem que haja nenhum acréscimo no atendimento ou no serviço médico efetivamente prestado. 
Em que pese o amplo apoio da classe médica à complementação dos honorários em caso de opção por acomodação superior, o Conselho Regional de Medicina do Estado do Paraná - CRM/PR (2010), no Parecer CRM/PR no 2142/2010, estabeleceu que os honorários médicos devem ser fixados de acordo com a natureza do serviço prestado, de modo que, não havendo diferenciação do atendimento médico, não haveria justificativa para a cobrança diferenciada de honorários, ante a vedação de discriminação e tratamento diferenciado. No parecer, o CRM/ PR destacou que a origem da cobrança diferenciada por acomodação, um vício que persiste até os dias atuais, está correlacionada à previsão normativa do INAMPS.

Entretanto, em 15/12/2014, a Terceira Turma do STJ, no julgamento do Recurso Especial no $1.178 .555-\mathrm{PR}$, que versava sobre ação civil pública objetivando declaração de nulidade de cláusula contratual de plano de saúde que previa o pagamento pelo usuário da complementação de honorários médicos em caso de solicitação de acomodação superior àquela prevista no contrato, entendeu, em voto relatado originado pelo ministro Ricardo Villas Bôas Cueva, ser "lícita a cobrança de honorários médicos complementares no setor privado, desde que seja acordado pelas partes e haja previsão contratual” (BRASIL, 2014, p. 7).

A interpretação consignada no precedente da Terceira Turma do STJ, por não ter eficácia vinculante, não logrou solucionar definitivamente a controvérsia sobre a abusividade dos honorários complementares. Em 26.02.2016, por exemplo, o Tribunal de Justiça de São Paulo decidiu que "a cláusula contratual que prevê o pagamento dos honorários médicos, caso o paciente opte por acomodação mais confortável é abusiva e ofende o princípio da boa-fé contratual” (art. 51, IV, CDC). Do teor do acórdão, destaca-se:

$$
\begin{aligned}
& \text { Correto reconhecimento da abusividade de cláusula } \\
& \text { que prevê a obrigação do usuário de pagar diferença de } \begin{array}{r}
\text { contratual } \\
\text { honorários } \\
\text { médicos caso opte por acomodação hospitalar superior à contratada. }
\end{array} \\
& \text { Importante mencionar que o contrato de plano de saúde é celebrado entre o consumidor } \\
& \text { e a operadora, não devendo aquele participar de negociações quanto aos honorários } \\
& \text { de médicos credenciados, especialmente pela motivação da referida cláusula, qual seja, } \\
& \text { escolha de acomodação superior à contratada (SÃO PAULO, 2016). }
\end{aligned}
$$

Ou seja, ainda se verifica uma oscilação pendular na jurisprudência em casos de cobrança de honorários médicos complementares caso o paciente opte por acomodação superior, ora entendendo ser abusiva tal cobrança, ora a tendo por legítima.

\section{DO DEVER DOS PLANOS DE SAÚDE DE INFORMAÇÃO PRÉVIA SOBRE A COMPLEMENTAÇÃO DOS HONORÁRIOS MÉDICOS}

O contrato de plano de saúde se traduz como a contratação de um fundo mutual para uso eventual de serviços de saúde. Seria um contrato aleatório e de trato sucessivo em que o agente/consumidor contrata um intermediário na prestação da saúde, nomeado de plano de saúde, que indicará um rol de profissionais e cobrirá os custos advindos do tratamento médico. O plano contratado, com a finalidade de controlar a demanda, fixa as franquias ou coparticipação como mecanismos de compartilhamentos de riscos e mitigação do risco moral (SATO, 2007; MAIA; ANDRADE; OLIVEIRA, 2004).

Os planos contribuíram decisivamente para a obsolescência da figura do "médico da família", pois os atendimentos se tornaram cada vez mais impessoais, notadamente pelo avanço e hiperespecialização médica (MASCARENHAS; GODINHO, 2016). 
No cenário do contratualismo, parte-se da ampla liberdade dos contratantes para definir as cláusulas que regulam suas relações. Ao revés, nos contratos de adesão, nos quais se enquadram os contratos de plano de saúde, verifica-se o predomínio da teoria contratual solidarista, com dirigismo contratual voltado à tutela do aderente, passando o contrato de simples fenômeno interpartes a instituto voltado à satisfação de interesse público e por meio do reconhecimento de sua função social. Sob essa perspectiva, o Estado passa a estabelecer um núcleo mínimo contratual para garantir a prevalência do interesse social sobre o meramente individual (TIMM, 2015).

Com o advento da Lei 9.656/98, também chamada de Lei dos Planos de Saúde (LPS), ficou estabelecido um núcleo mínimo de cobertura que deve ser contemplada por todos os contratos. Entretanto, tal marco legal foi silente quanto ao valor dos honorários médicos ou a forma de remuneração do profissional da medicina.

Desta forma, diante da omissão legislativa, os Conselhos Profissionais passaram a regular a remuneração profissional considerando os interesses corporativos, estabelecendo um valor ético mínimo, conforme se infere das normativas editadas no âmbito dos Conselhos Federal e Regionais de Medicina.

Nesse contexto, vários fundamentos indicam não ser juridicamente possível impor aos consumidores a observância da CBHPM. Em primeiro lugar, impende frisar a origem classista desta norma, criada exclusivamente para tutelar os interesses da classe médica.

Em segundo lugar, o art. $7^{\circ}$ do CDC prevê expressamente que os direitos ali previstos não excluem outros decorrentes de "regulamentos expedidos pelas autoridades administrativas competentes". O diálogo entre as fontes do microssistema consumerista jamais pode implicar, ante seu caráter protetivo e sua hierarquia constitucional ${ }^{9}$, que tais atos regulamentares venham criar encargos infundados para o consumidor.

Ademais, a imposição contratual que impõe ao consumidor aderente honorários complementares em razão de opção por acomodação superior afronta o art. 51, IV do CDC, que considera nulas de pleno direito as cláusulas contratuais que "estabeleçam obrigações consideradas iníquas, abusivas, que coloquem o consumidor em desvantagem exagerada, ou sejam incompatíveis com a boa-fé ou a equidade".

Assim, o poder regulamentar e disciplinar dos conselhos profissionais relativamente aos profissionais a si subordinados não os converte em poder legislativo paralelo, eis que sua atuação normativa criativa é adstrita à Constituição e às leis (MASCARENHAS, 2016).

Não se pode perder de vista que o contrato com os planos de saúde é dotado de natureza sucessiva e cuja legítima expectativa é a base da contratação. A ausência de informação expressa e destacada (CDC, art. 46 e 54, $\S 4^{\circ}$ ) de que a contratação de acomodação superior importa em uma majoração de honorários médicos, além de despropositada em razão do pagamento, por parte do plano, do serviço pago, indica uma omissão dolosa que viola os direitos do consumidor e prejudica o cumprimento contratual e os próprios fundamentos de existência do plano (BONIZZATO; MARTINS, 2014; SANTOS, 2016).

Logo, apesar de existir uma relação contratual entre consumidor e profissional, esta só ocorre após a intermediação promovida pelo plano, de modo que este não pode ser considerado na construção do relacionamento, consoante se infere da Figura o1 abaixo.

9 A Constituição Federal erigiu a defesa do consumidor ao patamar de direito coletivo fundamental (art. $5^{\circ}$, XXXII) e princípio geral da ordem econômica (art. 170, V), além de determinar a edição do Código de Defesa do Consumidor (ADCT, art. 48). 
Figura o1 - Relação contratual no âmbito dos planos de saúde

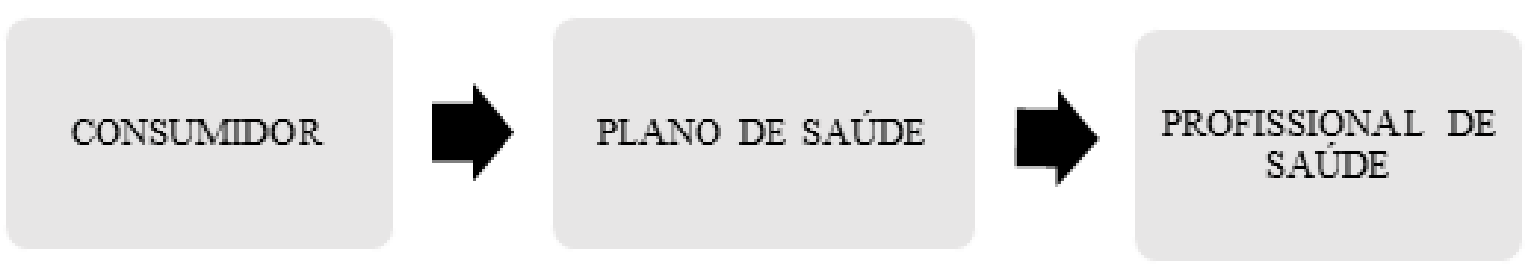

Fonte: Elaborada pelos autores, 2018.

Pagamentos e honorários são fixados pelo plano e visam remunerar o serviço médico prestado, de maneira que eventual cobrança extraordinária em razão de acomodação superior viola a premissa básica de intermediação financeira promovida pelo plano, criando uma espécie de remuneração híbrida que não se confunde com o controle de demanda através das franquias ou coparticipação, mas que exige, de fato, uma remuneração por um serviço médico já contratado e pago.

Nesse sentido, já destacou o Tribunal de Justiça do Rio Grande do Sul que a remuneração extra por acomodação superior só seria cabível se existente prova de concordância por parte do paciente, não cabendo a extensão dos efeitos da resolução do CFM para a relação consumerista:

Não se desconhece a possibilidade de que despesas extras, não cobertas por planos de saúde, sejam suportadas pelo paciente, assim como eventual acréscimo em decorrência da opção por serviço superior ao contratado.

\section{$[\ldots]$}

Veja-se que a mencionada Resolução 1.673/o3 do Conselho Federal de Medicina não tem a extensão invocada - autorizando a cobrança em dobro dos honorários em casos de alteração de acomodação (RIO GRANDE DO SUL, 2015).

Nesse sentido, o art. 46 do CDC estabelece que os contratos de consumo "não obrigarão os consumidores se não lhes for dada a oportunidade de tomar conhecimento prévio de seu conteúdo, ou se os respectivos instrumentos forem redigidos de modo a dificultar a compreensão de seu sentido e alcance". Assim, ainda que se considere válida a cláusula que prevê a cobrança de honorários complementares em caso de acomodação superior, os percentuais e valores acrescidos devem vir consignados em destaque no contrato (CDC, art. 54 , $§ 4^{\circ}$ ), não se admitindo remissão genérica à CBHPM, sob pena de ineficácia relativamente ao consumidor aderente.

O dever de informação, corolário da boa-fé contratual, surge como mecanismo de defesa para os consumidores a exigir transparência e simetria de dados nas transações (VASCONCELOS, 2011). A informação serve como mecanismo de mitigação de risco, de forma que o consumidor não seja surpreendido por dívida que não previu e que não poderia contabilizar, além de ser instrumento fundamental para a tomada de escolhas conscientes, a partir dos riscos e consequências previamente conhecidos (SANTOS, 2016). 


\section{DA ABUSIVIDADE DA MAJORAÇÃO DOS HONORÁRIOS MÉDICOS POR ACOMODAÇÃO SUPERIOR}

O art. 6º II, do CDC erige a igualdade nas contratações a direito básico dos consumidores, impondo a obrigatoriedade de tratamento idêntico às pessoas que se encontrem na mesma situação.

Pelo princípio da impessoalidade da administração pública (CF, art. 37, caput), o ordenamento jurídico também proíbe a administração pública de dispensar tratamentos desiguais para pessoas que estão em situação análoga, sob pena de violação do preceito constitucional da igualdade.

Não é possível a realização de tratamento desigual de forma arbitrária, de modo que o Estado deve motivar a sua opção de tratamento desigual para que haja a possiblidade de controle dos fundamentos que justifiquem o tratamento não igualitário (GONÇALVES, 2010).

Não há fundamento lógico, jurídico ou mesmo econômico que demonstre um nexo de causalidade entre a mudança de acomodação para nível superior e a natureza, qualidade ou custo do serviço médico prestado. $\mathrm{O}$ respeito à dignidade da pessoa humana exige esforços máximos por parte do profissional, de modo que não pode haver um escalonamento de tratamento por motivos econômicos ou sociais do paciente, tampouco em razão da acomodação.

A mudança de acomodação não importa em qualquer ônus para o profissional médico, de modo que o suposto tratamento diferenciado teria função meramente de captura da razão do excedente econômico existente pelo consumidor. A falta de fundamento jurídico caracteriza a abusividade da conduta.

As prestações devem respeitar a justiça contratual, caracterizada pela equidade e proporção entre as obrigações. O caráter aleatório do contrato não retira a justa correspondência entre as prestações, que aqui assumem uma relação atuarial. No serviço médico, a prestação profissional está absolutamente dissociada da acomodação escolhida pelo paciente-consumidor. Desta forma, se as prestações são fixadas aprioristicamente, a mudança da acomodação não altera a obrigação médica, de sorte que a complementação de honorários se configura em cláusula abusiva, pois indicaria um enriquecimento sem causa e resultaria na proibição constante no art. 39, V do CDC: “Art. 39. É vedado ao fornecedor de produtos ou serviços, dentre outras práticas abusivas: $\mathrm{V}$ - exigir do consumidor vantagem manifestamente excessiva;".

A ausência de fundamento para a diferenciação dos honorários médicos em razão da acomodação do paciente caracteriza a abusividade de sua cobrança, sendo vedado ao profissional se aproveitar da vulnerabilidade do consumidor para impor-lhe prestação manifestamente excessiva, sem qualquer respaldo legal.

De acordo com a doutrina clássica de Ripert (2002), não se pode consagrar uma liberdade absoluta contratual, uma vez que o contrato não pode ser interpretado exclusivamente a partir do dogma da vontade, notadamente pelo contrato ser instrumento de "luta de vontades egoístas", em que cada uma das partes busca garantir uma maior vantagem a um custo de sacrifício menor.

Desta forma, impor, em razão de uma normativa classista, a obrigatoriedade de o consumidor pagar um adicional de honorários médicos apenas por ter mudado de acomodação denota que a figura do contrato tem sido deformada em favor de uma classe mais poderosa e em uma situação em que o consumidor está em flagrante vulnerabilidade, notadamente por seu quadro exigir uma internação. A falta de qualquer custo para a prestação do serviço de acordo com a acomodação exige os mesmos honorários médicos, sob pena de violação da isonomia e abusividade da conduta. 


\section{CONSIDERAÇÕES FINAIS}

Embora, em suas origens, as profissões da saúde se remetam ao ideal de honorabilidade que as afasta da mercantilização, a complexidade e a profissionalização dos agentes econômicos que atualmente exploram tais atividades no mercado impõem que a relação médico-paciente seja concebida sob perspectiva consumerista, consoante já sedimentado pela jurisprudência brasileira, de modo que o paciente, além da vulnerabilidade que o caracteriza, torna-se hipervulnerável por também ser consumidor.

A dupla vulnerabilidade do paciente/consumidor se agudiza no momento da fixação e cobrança da remuneração devida ao profissional da medicina, fase que propicia a implementação de práticas comerciais abusivas e viabiliza a inserção de cláusulas contratuais excessivamente onerosas, a exemplo da complementação dos honorários médicos por acomodação superior.

Tal prática tem origem nas Portarias 2079/1980/INAMPS e MPAS 2837/1982, que previam a possibilidade de que hospitais privados repassassem para os pacientes parte do custo do serviço, quando houvesse opção por acomodações especiais.

A partir daí entidades médicas, pautadas por interesses eminentemente corporativos, replicaram, na CBHPM, sem qualquer justificativa razoável, a lógica da majoração dos honorários médicos quando houvesse opção do paciente por acomodações superiores.

Ocorre que a natureza consumerista dos serviços médicos, que atrai a incidência do microssistema protetivo do consumidor, impõe aos profissionais da medicina a observância do princípio da isonomia e da igualdade das contratações. Nesta perspectiva, configura prática flagrantemente abusiva exigir do paciente-consumidor complementação dos honorários profissionais, sem que haja qualquer serviço ou tratamento adicional.

Embora existissem precedentes de tribunais estaduais considerando ilegal a majoração de honorários por simples mudança de acomodação do paciente, a Terceira Turma do STJ, em dezembro de 2014, no julgamento do Recurso Especial no 1.178.555-PR considerou esta prática legítima, arrefecendo a intensa discussão jurídica que se travava sobre tal temática.

Nada obstante, é importante ter em mente que este julgado do STJ se configura em mero precedente jurisprudencial, sem força vinculante, que exprime posição de apenas uma das turmas de direito privado daquele tribunal superior, em julgado ocorrido há quase quatro anos.

Deste modo, devemos retomar o debate em torno da abusividade da majoração de honorários médicos por acomodação superior, não havendo óbice para que os tribunais estaduais, a Quarta Turma do STJ ou mesmo a própria Terceira Turma do Tribunal da Cidadania - cuja composição não é a mesma de 2014 - passem a considerar ilegal a cobrança de complementação de honorários médicos sem que exista nenhum tratamento médico ou serviço adicional.

\section{REFERÊNCIAS}

BONIZZATO, Luigi; MARTINS, Flávio Alves. Saúdes pública e privada e relações de consumo: uma análise constitucional e civilística de responsabilidades estatais, pré e pós-contratuais no Brasil. Revista de Direito do Consumidor, São Paulo, v. 96, n. 23, p. 109-138, nov./dez. 2014. 
BRASIL. Superior Tribunal de Justiça. Recurso Especial no 1.178.555-PR. Terceira Turma. Relator Ministro Ricardo Villas Bôas Cueva. Julgado em 09/12/2014. DJe, Brasília, 15 dez. 2014. Disponível em: <http://www.stj.jus.br/SCON/jurisprudencia/toc.jsp?processo= 1178555\&\&b=ACOR\&thesaurus=JURIDICO\&p=true>. Acesso em: 13 fev. 2018.

CALADO, Vinicius Negreiros. Responsabilidade civil do médico e consentimento informado: um estudo interdisciplinar dos julgados do STJ. Curitiba: Juruá, 2014.

CHERCHIGLIA, Mariangela. Remuneração do trabalho médico: um estudo sobre seus sistemas e formas em hospitais gerais de Belo Horizonte. Cadernos de Saúde Pública, v. 10, p. 67-79, 1994 .

CONSELHO REGIONAL DE MEDICINA DO ESTADO DE SANTA CATARINA. Manual de orientação ética e disciplinar. CRM/SC, 200o. Disponível em: <http://www.portalmedico.org. $\mathrm{br} / \mathrm{regional} / \mathrm{crmsc} / \mathrm{manual} /$ partezi.htm>. Acesso em: 13 fev. 2018.

DANTAS, Eduardo; COLTRI, Marcos Vinicius. Comentários ao Código de Ética Médica: Resolução CFM n ${ }^{\circ}$ 1.931, de 17 de setembro de 2009. Rio de Janeiro: GZ Ed., 2010.

MATOS, Júlio Flavio Dornelles de; PAIM, Cristiane. Da constitucionalidade da internação hospitalar na modalidade diferença de classe. Cadernos Ibero-Americanos de Direito Sanitário, v. 4, n. 1, p. 81-85, 2015.

FONSECA, Pedro; FONSECA, Maria Paula. Direito do Médico: De acordo com o novo CPC. Belo Horizonte: D’Plácido, 2016.

FRANÇA, Genival Veloso. Comentários ao Código de Ética Médica. 6. ed. Rio de Janeiro: Guanabara Koogan, 2010.

Direito Médico. Rio de Janeiro: Forense, 2013.

GONÇALVES, Rogério Magnus Varela. Princípio constitucional da igualdade. Direito e Desenvolvimento, v. 1, n. 2, p. 121-133, 2010.

KFOURI NETO, Miguel. Responsabilidade civil do médico. 8. ed. São Paulo: Revista dos Tribunais, 2013.

MAIA, Ana Carolina; ANDRADE, Mônica Viegas; OLIVEIRA, Ana Maria Hermeto Camilo de. O risco moral no sistema de saúde suplementar brasileiro. In: XXXII Encontro Nacional de Economia. João Pessoa. Anais... João Pessoa, 2004.

MARTINS, Ives Gandra da Silva. Parecer 721/10 - Controle Concentrado de Constitucionalidade. Advocacia Gandra Martins. 2010. Disponível em: <http://www.gandramartins.adv.br/ parecer/detalhe/id/PAoo474>. Acesso em: 03 fev. 2018. 
MASCARENHAS, Igor de Lucena. O Legislativo Paralelo: a atuação do Conselho Federal de Medicina na criação de tipos normativos. In: BRAUNER, Maria Cláudia Crespo; APÓLITO, Maite Rodriguez (Org.). Biodireito e direitos dos animais. Florianópolis: CONPEDI, 2016. p. 171-187.

MASCARENHAS, Igor de Lucena; GODINHO, Adriano Marteleto. A utópica aplicação da teoria da perda de uma chance no âmbito do direito médico: uma análise da jurisprudência do TJRS, TJPR e TJPE. Revista Direito e Liberdade-RDL-ESMARN, v. 18, n. 3, p. 159-192, 2016.

MELO, Nehemias. Responsabilidade civil por erro médico: doutrina e jurisprudência. 3. ed. São Paulo: Atlas, 2014.

MENICUCCI, Telma Maria Gonçalves. Público e privado na política de assistência à saúde no Brasil: atores, processos e trajetórias. Rio de Janeiro: Editora Fiocruz, 2007.

PEREIRA, André Gonçalo Dias. Direito dos pacientes e responsabilidades médicas. Coimbra: Coimbra Editora, 2015.

RAPOSO, Vera Lúcia. Do ato médico ao problema jurídico. Coimbra: Almedina, 2013.

RIO GRANDE DO SUL. Tribunal de Justiça do Estado do Rio Grande do Sul. AC: 70048762926 RS, Relator: Ana Maria Nedel Scalzilli, Data de Julgamento: 24/o9/2015, Décima Sexta Câmara Cível. DJ, Porto Alegre, 28 set. 2015.

RIPERT, Georges. A regra moral nas obrigações civis. Campinas: Bookseller, 2002.

SANTOS, Fabíola Meira de Almeida. Informação como instrumento para amenizar riscos na sociedade de consumo. Revista de Direito do Consumidor, São Paulo, v. 107, n. 25, p. 363384, set./out. 2016.

SÃO PAULO. Tribunal de Justiça do Estado de São Paulo. APL: 00272022820058260114 SP 0027202-28.2005.8.26.0114, Relator: Alexandre Lazzarini, Data de Julgamento: 23/02/2016, 9a Câmara de Direito Privado. DJ, São Paulo, 24 fev. 2016.

SATO, Fábio Ricardo Loureiro. A teoria da agência no setor da saúde: o caso do relacionamento da Agência Nacional de Saúde Suplementar com as operadoras de planos de assistência supletiva no Brasil. Revista de Administração Pública, v. 41, n. 1, p. 49-62, 2007.

SZAFIR, Dora. Responsabilidad médica: Consumidor o usuário de servicios de salud. Cuadernos del Anuario de Derecho Civil Uruguayon, 16, Montevidéo: Fundácion de Cultura Universitária, 2015.

TEPEDINO, Gustavo. Tutela contractual del consumidor en Brasil. Trabajo presentado en VII Jornadas Internacionales de relaciones de consume - A diez años de la LEY 17.250. Temas de Derecho de Consumo. Montevidéo: Fundación de Cultura Universitaria, 2010.

TIMM, Luciano Benetti. Direito Contratual Brasileiro: críticas e alternativas ao solidarismo jurídico. 2. ed. São Paulo: Atlas, 2015. 
VASCONCELOS, Fernando. Proteção do consumidor na área da saúde: responsabilidade civil de médicos, hospitais e planos de saúde. Direito e Desenvolvimento, v. 2, n. 2, p. 266-281, 2011. 